\title{
Understanding balloon-borne frost point hygrometer measurements after contamination by mixed-phase clouds
}

Teresa Jorge et al.

Correspondence to: Teresa Jorge (teresa.jorge@env.ethz.ch)

The copyright of individual parts of the supplement might differ from the CC BY 4.0 License. 


\section{Flight NT029}

Here we analyse the contamination during flight NT029. The figures shown in this appendix are analogous to several figures shown in the main body of the paper. Figure S1 shows the full profile of flight NT029 on 30 August 2016. As for the flight NT011, there were contaminated water vapour mixing ratios in the stratosphere, and recovery of operation of the CFH still during ascent before balloon burst. The COBALD (panel c) observed three clouds: one very thin cloud in the liquid phase regime, at air temperatures higher than $0^{\circ} \mathrm{C}$; a second could, in the mixed-phase regime with very interesting features in the BSR and $\mathrm{Cl}$; and a third cloud at air temperature lower than $-38^{\circ} \mathrm{C}$, which was in the cirrus or ice cloud regime. We did not consider the liquid cloud to be the source of the contamination, because the cloud finished at $T=0^{\circ} \mathrm{C}$ and between the end of the liquid cloud and the start of the mixed-phase cloud the payload went through a sub-saturated region. Liquid water on the intake tube wall would evaporate in the sub-saturated region.

Figure S2 shows a detail of the mixed-phase cloud of flight NT029. The mixed-phase cloud existed between the temperatures of $-15^{\circ} \mathrm{C}$ and $-21^{\circ} \mathrm{C}$, when $S_{\text {ice }}$ by the CFH was between 1.1 and $1.05, S_{\text {liq }}$ by the RS 41 was between 0.95 and 0.85 , and the $\mathrm{Cl}$ was above 20 . This confined the mixed-phase cloud to the interval between 8.1 and $9.1 \mathrm{~km}$ altitude.

Figure S3 shows the cloud modelling results for the mixed-phase cloud shown in Figure S2. From the integration of water vapour in the upper troposphere and stratosphere of flight NT029 (see Table 3 of Jorge et al., 2020), we determined the upper and lower estimates of liquid water content (LWC) of this mixed-phase cloud to be $0.160 \mathrm{~g} \mathrm{~m}^{-3}$ and $0.032 \mathrm{~g} \mathrm{~m}^{-3}$ respectively (see Table 1 of Jorge et al., 2020). For the simulation, we defined the initial distribution with the same ice crystal and liquid droplets sizes as for the NT011 cloud modelling: $r_{\text {ice }}=10 \mu \mathrm{m}, r_{\text {liq }, 1}=10 \mu \mathrm{m}, r_{\text {liq }, 2}=100 \mu \mathrm{m}$, and $r_{\text {liq }, 3}=200 \mu \mathrm{m}$. The bigger droplets extended the glaciation time and prolonged the duration of the cloud liquid phase. The initial ice crystal concentration was the same as the expected for ice nucleation particles (INP) at these temperatures: $n_{\text {ice }}=0.02 \mathrm{~cm}^{-3}$ (DeMott et al., 2010). The upper estimate of LWC started with $n_{\text {liq, } 1}=70 \mathrm{~cm}^{-3}$ and $n_{\text {liq }, 2}=0.030 \mathrm{~cm}^{-3}$ and the lower estimate of LWC started with $n_{\text {liq }, 1}=30 \mathrm{~cm}^{-3}$ and $n_{\text {liq }, 2}=0.002 \mathrm{~cm}^{-3}$, both simulations had $n_{\text {liq }, 3}=0.001 \mathrm{~cm}^{-3}$. Both upper and lower estimate clouds existed for about $\Delta t \sim 40$ minutes at the $S_{\text {liq }}$ and $S_{\text {ice }}$ conditions observed in the NT029 mixed-phase cloud. The average velocity of the payload in this part of the flight was $6 \mathrm{~m} \mathrm{~s}^{-1}$, which means the payload was in the 1000-m-long cloud for about 3 minutes.

Figure S4 shows the pendulum analysis for the mixed-phase cloud of flight NT029. We observed payload oscillations with up to $40 \mathrm{~m}$ amplitude. Figure $\mathrm{S} 5$ summarizes the observed velocities $\left(v_{\perp}\right)$ perpendicular to the intake tube, ascent velocities parallel $\left(w_{\|}\right)$to the intake tube and impact angles $(\beta)$ experienced during the mixed-phase cloud of flight NT029.

Figure $\mathrm{S} 6$ shows the FLUENT simulations results for the collision/ freezing efficiency of hydrometeors inside the intake tube for flight NT029. We only show results for $100 \mu \mathrm{m}$ radius droplets. The results for $200 \mu \mathrm{m}$ droplets were very similar to the ones shown in Figure S14. As for flight NT011, all big droplets froze on the intake tube wall. Again, with higher impact angles, the freezing efficiency was higher at the top of the intake tube. The ice layer thickness for the first $5 \mathrm{~cm}$ of the intake tube are shown in Figure S6k for the two estimates of LWC in the mixed-phase cloud.

Figure S7 shows the stratosphere of flight NT029, and the FLUENT simulation results (see also Table S1). The ascent velocity for NT029 was less variable, about $\pm 1 \mathrm{~m} \mathrm{~s}^{-1}$, than for flight NT011. From the comparison of the simulation results for $\chi_{\mathrm{H}_{2} \mathrm{O}}$ in Figure S7b, we concluded, as for flight NT011, that the simulations with $5 \mathrm{~cm}$ ice coverage of the intake tube yielded the best description of the observations. The contamination was more 
persistent for flight NT029 than for flight NT011, i.e. it lasted longer, but the burst was also at higher altitude. The measurement started recovering at $26 \mathrm{~km}$ altitude. At $27.5 \mathrm{~km}$ altitude, the simulation for a $1 \mathrm{~cm}$ ice coverage of the intake tube matched the observed $\chi_{\mathrm{H}_{2} \mathrm{O}}$. At higher altitude levels, simulations with smaller ice coverages such as thinner layers of $0.15 \mathrm{~cm}$ length, and radially asymmetric patches as shown in Figure $10 \mathrm{~g}$ of Jorge et al., 2020 or smaller, extending only for $0.45 \mathrm{~cm}$ instead of $1 \mathrm{~cm}$, matched the observations. Above $30.5 \mathrm{~km}$ altitude, we considered the measurement to be recovered.

Regarding contamination in the upper troposphere for flight NT029, we considered two regions where sublimation of ice inside the intake tube could have happen: from $11 \mathrm{~km}$ altitude to the start of the cirrus cloud, where $S_{\text {ice }}<1$, and from above the cirrus cloud at $15.5 \mathrm{~km}$ altitude to the CPT, which are shown in Figure S8. We excluded the region directly above the mixed-phase cloud, from 9 to $11 \mathrm{~km}$ altitude. The backscatter ratio, as can be seen in Figure S1d and S2b, was very perturbed and $S_{\text {ice }}>1$, so, it was possible that the payload was in cloud. We also did not consider the cirrus cloud region. At $S_{\text {ice }}=1$ there would be no sublimation of the ice inside of the intake tube. In the upper troposphere of flight NT029 (Figure S8), we noticed again the dry bias of the RS41 in relation to the $\mathrm{CFH}$. At the three lower altitudes in the upper troposphere $(12.2 \mathrm{~km}, 12.7 \mathrm{~km}$ and $15.6 \mathrm{~km}$, see Table S1) for which we ran simulations, there is good agreement between the $\chi_{\mathrm{H}_{2} \mathrm{O}}$ of the simulation with $15 \mathrm{~cm}$ ice coverage inside the intake tube and the $\chi_{\mathrm{H}_{2} \mathrm{O}}$ measured by the $\mathrm{CFH}$. At $16.5 \mathrm{~km}$ altitude, the simulation with $5 \mathrm{~cm}$ ice coverage inside the intake tube showed the best agreement with the observations.

The excess integrated water vapour in the stratosphere of NT029 was $15.7 \mathrm{mg}$. The excess integrated water vapour in the upper troposphere of NT029 was $3.5 \mathrm{mg}$ for the lower sub-saturated region between the mixedphase cloud and the cirrus cloud, and $60.5 \mathrm{mg}$ between the cirrus cloud and the tropopause. The total excess integrated water vapour in flight NT029 was $79.7 \mathrm{mg}$. All these values are in Table 3 of Jorge et al., 2020. 

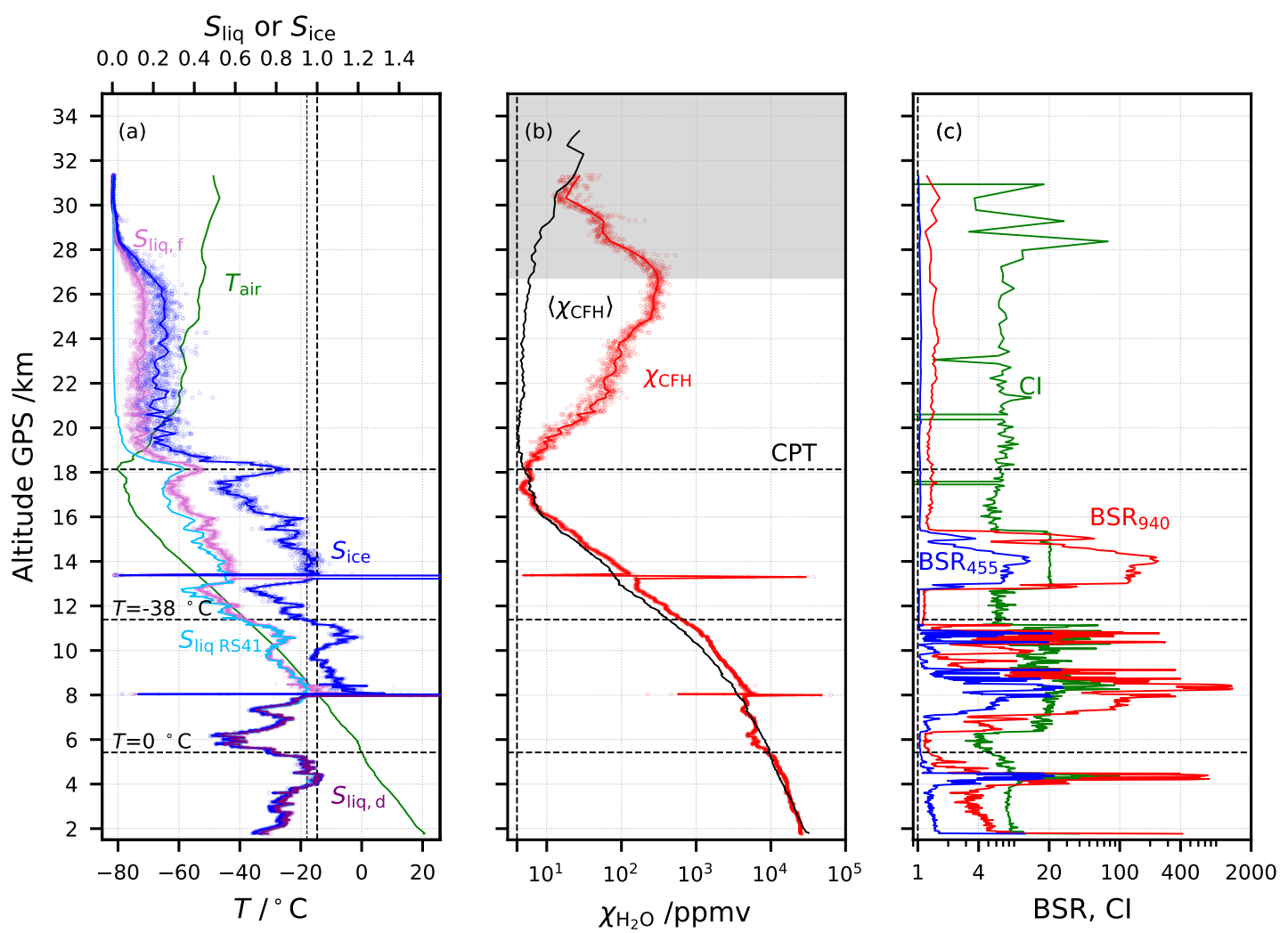

Figure S1: Flight NT029 in Nainital, India, on 30 August 2016. Lines: 1 hPa interval averaged values. Dots: $1 \mathrm{~s}$ data. (a) Green: air temperature measurement from the Vaisala RS41; light blue: relative humidity ( $S_{\text {liq RS41 }}$ ) by the RS41; blue: ice saturation ( $\left.S_{\text {ice }}\right)$ from the CFH; purple: saturation over water $\left(S_{\text {liq, }}\right)$ from the CFH considering the deposit on the mirror to be dew; pink: saturation over water $\left(S_{\text {liq, } f}\right)$ from the CFH considering the deposit on the mirror to be frost. Note that the condensate on the CFH mirror was forced to turn from dew to frost after the freezing cycle, at $T_{\text {frost }}=-15{ }^{\circ} \mathrm{C}$. (b) Red: $\mathrm{H}_{2} \mathrm{O}$ mixing ratio from the $\mathrm{CFH}$ in ppmv; black: season average $\mathrm{H}_{2} \mathrm{O}$ mixing ratio excluding contaminated CFH profiles for the Nainital 2016 summer campaign (Brunamonti et al., 2018). Highlighted values with grey shading above the $20-\mathrm{hPa}$ level are possibly contaminated by out gassing from the balloon envelope. 'CPT' marks the cold point tropopause. (c) Red: 940-nm backscatter ratio from the COBALD; blue: same for $455 \mathrm{~nm}$; green: color index $(\mathrm{Cl})$ from the COBALD. 

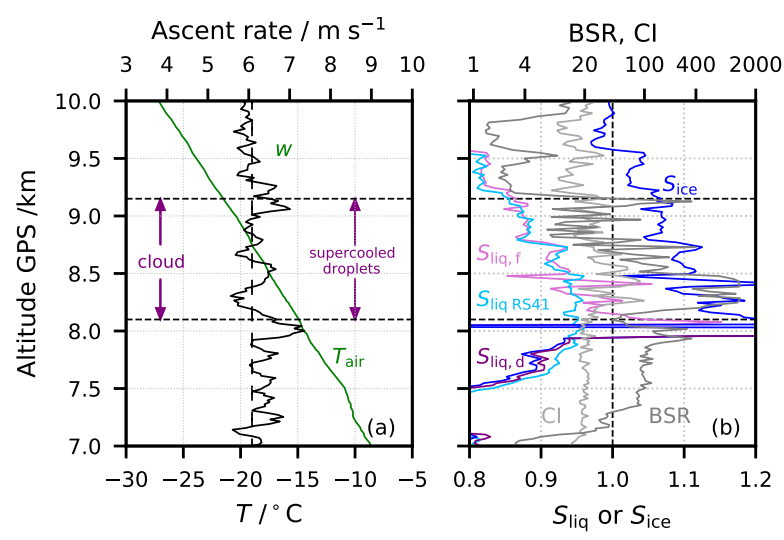

Figure S2: Mixed-phase cloud detail of flight NT029. Lines: $1 \mathrm{hPa}$ interval averaged values. (a) Green: air temperature; black: ascent velocity measured by the RS41 in $\mathrm{m} \mathrm{s}^{-1}$. (b) Light blue: saturation over water ( $\left.S_{\text {liq RS41 }}\right)$ measured by the RS41; purple: saturation over water $\left(S_{\text {liq, }}\right)$ from the CFH considering the deposit on the mirror to be dew; pink: saturation over water $\left(S_{\text {liq, }}\right)$ from the CFH considering the deposit on the mirror to be frost; blue: ice saturation $\left(S_{\text {ice }}\right)$ from the $\mathrm{CFH}$; dark grey: 940-nm backscatter ratio from the COBALD; light grey: color index $(\mathrm{Cl})$ from the COBALD. Horizontal dashed lines mark supercooled droplet region.

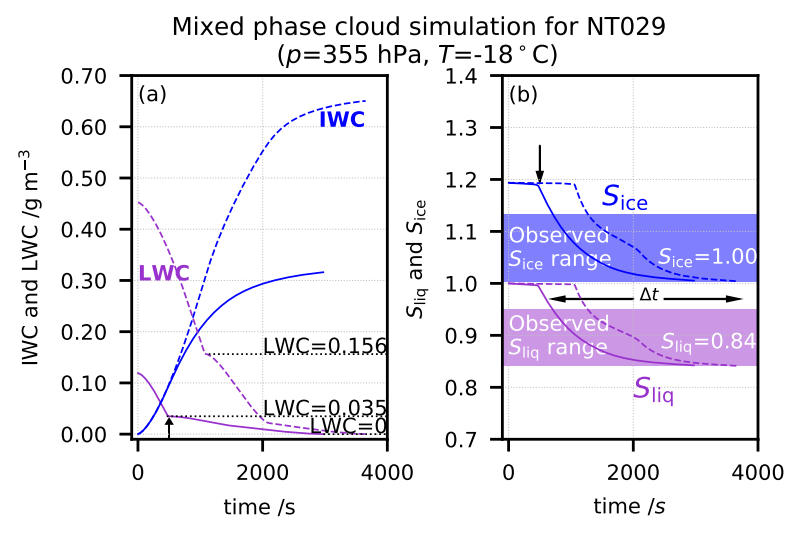

Figure S3: Modelling of the Wegener-Bergeron-Findeisen process in mixed-phase cloud demonstrating that flight NT029 likely encountered supercooled liquid droplets. Solid lines: lower estimate of liquid water content (LWC). Dashed lines: upper estimate (see text). Initial size distributions for lower estimate simulation: $n_{\text {ice }}=0.02 \mathrm{~cm}^{-3}, r_{\text {ice }}=10 \mu \mathrm{m} ; n_{\text {liq }, 1}=20 \mathrm{~cm}^{-3}, r_{\text {liq }, 1}=10 \mu \mathrm{m} ; n_{\text {liq }, 2}=0.002 \mathrm{~cm}^{-3}$, $r_{\text {liq }, 2}=100 \mu \mathrm{m} ; n_{\text {liq }, 3}=0.001 \mathrm{~cm}^{-3}, r_{\text {liq }, 3}=200 \mu \mathrm{m}$. Initial size distributions for upper estimate simulation are identical but with $3.5 \times$ larger $n_{\text {liq }, 1}$ and $15 \times \operatorname{larger} n_{\text {liq, } 2}$. (a) Blue: ice water content (IWC); purple: liquid water content (LWC); vertical arrows: time when smaller liquid droplets fully evaporated. (b) Blue: ice saturation ratio $\left(S_{\text {ice }}\right)$; purple: liquid water saturation ratio $\left(S_{\text {liq }}\right)$ for lower and upper estimates. Glaciation times of small droplets $\tau_{g, 1} \sim 8$ - 18 minutes, of big droplets $\tau_{g, 2-3} \sim 45-50$ minutes. Shaded saturation ratios: observed ranges from Figure 52 . The computed time interval with $S_{\text {ice }}$ and $S_{\text {liq }}$ matching flight observations is $\Delta t \sim 30$ - 40 minutes. 

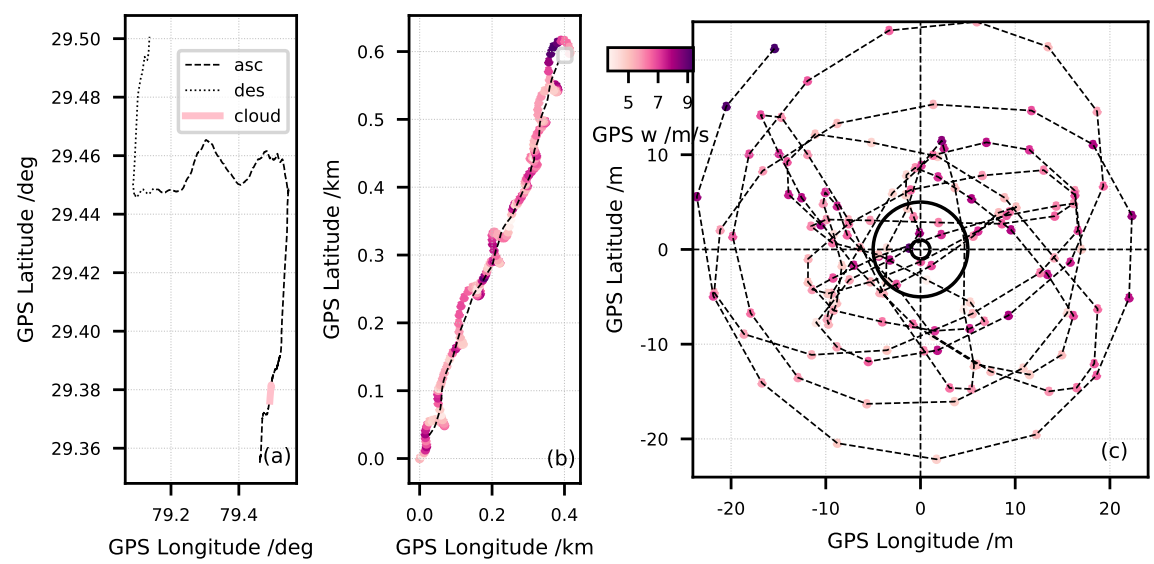

Figure S4: Pendulum analysis for mixed-phase cloud of flight NT029. (a) Payload trajectory: ascent (dashed), descent (dotted) and mixed-phase cloud between 8.1 and $9.15 \mathrm{~km}$ altitude (thick pink line). (b) Zoom in on the mixed-phase cloud with 1-second GPS data of payload trajectory (symbols) and balloon trajectory (dashed). (c) Detrended payload oscillations; approximate balloon sizes on the ground $(r=1 \mathrm{~m})$ and at burst $(r=5 \mathrm{~m})$ are shown by two circles. Colour code in (b) and (c): balloon ascent velocity.
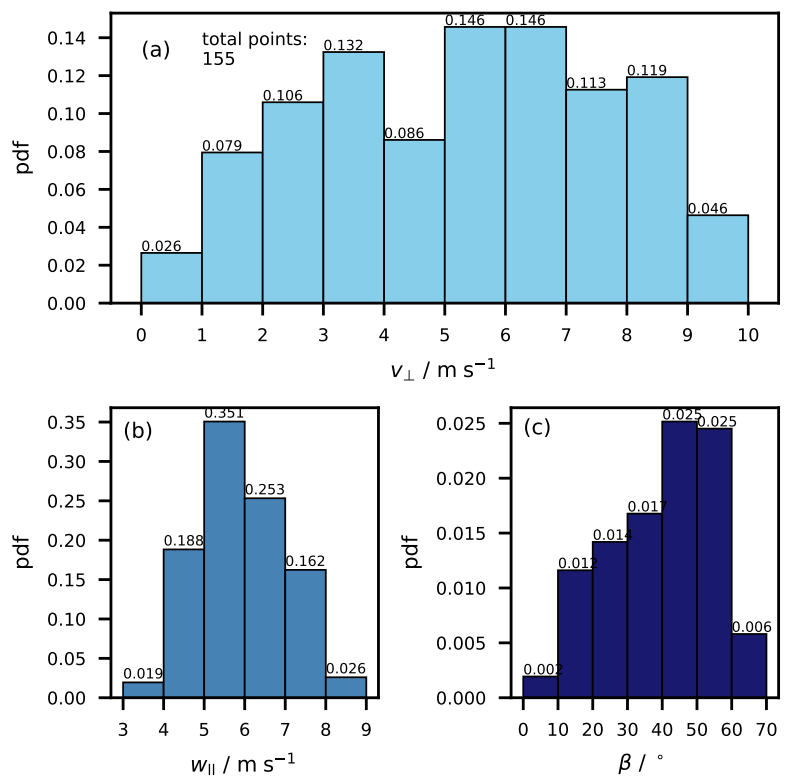

Figure S5: Probability density functions (pdf) of impact parameters at the inlet plane of the CFH intake tube during the passage through the mixed-phase cloud of flight NT029. (a) Velocity $v_{\perp}$ perpendicular to the tube walls; (b) velocity $w_{\|}$parallel to the axis of the tube; $(c)$ impact angle $(\beta)$. 


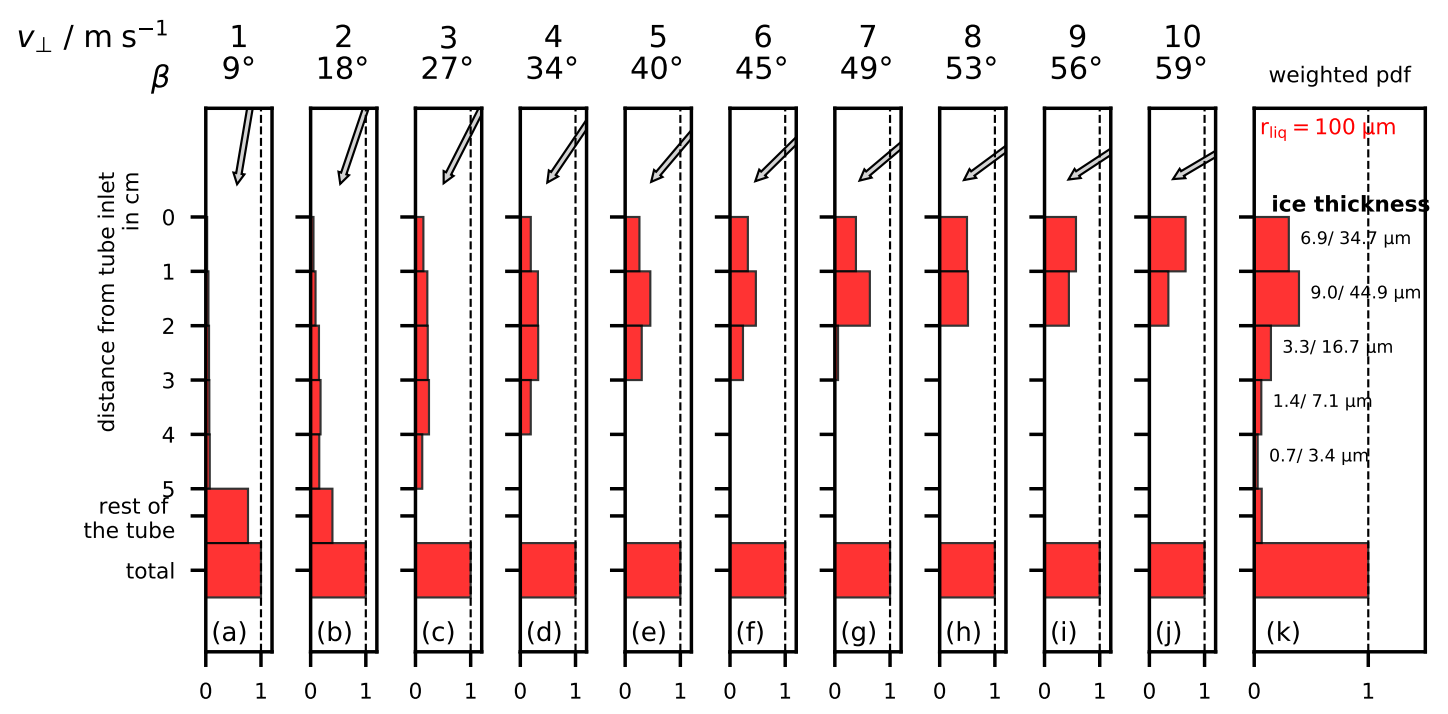

Figure S6: Collision/freezing efficiency of hydrometeors in the intake tube for the flight NT029 mixedphase cloud with average vertical inlet velocity $w_{\|}=6.0 \mathrm{~m} \mathrm{~s}^{-1} . r_{\text {liq }}=100 \mu \mathrm{m}$ (red). (a-j) Freezing efficiency for various velocities $\left(v_{\perp}\right)$ perpendicular to the tube walls: (a) $1 \mathrm{~m} \mathrm{~s}^{-1}, 9^{\circ}$; (b) $2 \mathrm{~m} \mathrm{~s}^{-1}, 18^{\circ}$; (c) $3 \mathrm{~m} \mathrm{~s}^{-1}, 27^{\circ}$; (d) $4 \mathrm{~m} \mathrm{~s}^{-1}, 34^{\circ}$; (e) $5 \mathrm{~m} \mathrm{~s}^{-1}, 40^{\circ}$; (f) $6 \mathrm{~m} \mathrm{~s}^{-1}, 45^{\circ}$; (g) $7 \mathrm{~m} \mathrm{~s}^{-1}, 49^{\circ}$; (h) $8 \mathrm{~m} \mathrm{~s}^{-1}$, $53^{\circ}$; (i) $9 \mathrm{~m} \mathrm{~s}^{-1}, 56^{\circ}$; (j) $10 \mathrm{~m} \mathrm{~s}^{-1}, 59^{\circ}$. The 'rest of the tube' takes account of all collisions occurring deeper than $5 \mathrm{~cm}$ inside the tube, including the mirror holder. ( $\mathrm{k}$ ) Weighted sum of the efficiencies in panels (a-j) by the horizontal velocity pdf of Figure S5a, in front of each bar we write the thickness of the subsequent ice layer considering radially homogeneous cover of the intake tube and the lower (left) and upper (right) LWC estimate for the cloud. 

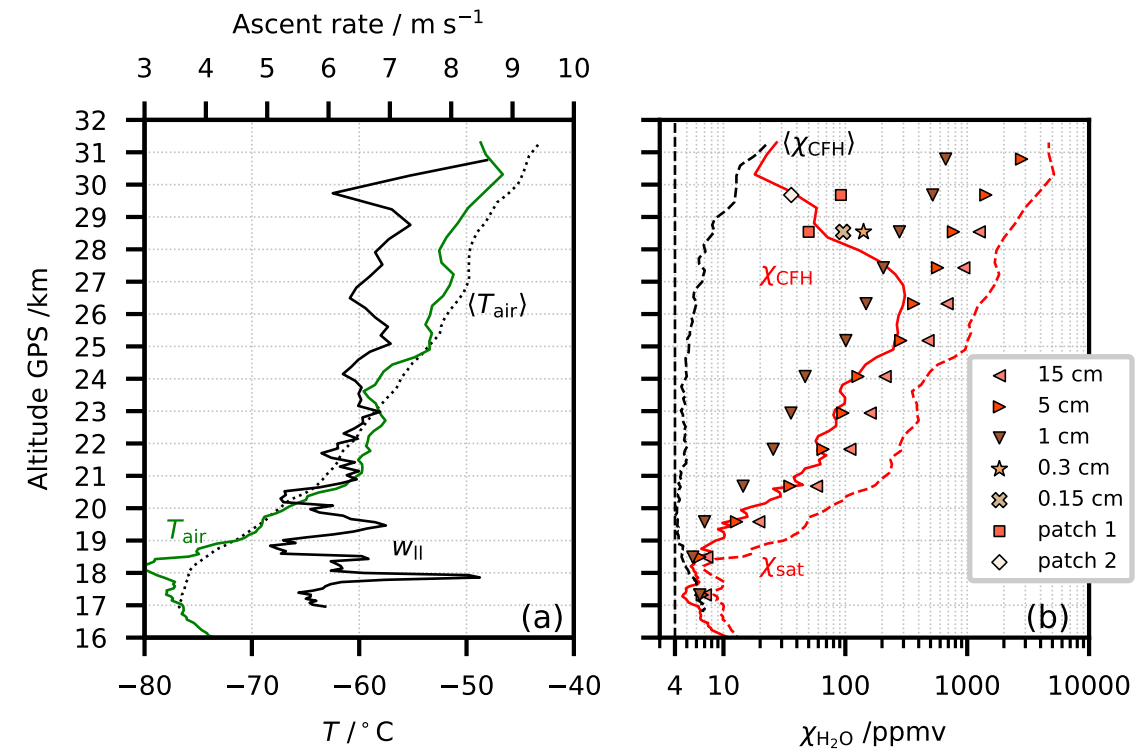

Figure S7: Flight NT029 and FLUENT simulation results for sublimation of ice in the intake tube in the stratosphere. (a) Green line: measured air temperature $T_{\text {air }}$; dotted black line: average air temperature for the 2016 Nainital summer campaign; solid black line: ascent velocity. (b) Solid red line: $\mathrm{H}_{2} \mathrm{O}$ mixing ratio measured by the CFH during NTO29 $\left(\chi_{\mathrm{CFH}}\right)$; dashed black line: average $\mathrm{H}_{2} \mathrm{O}$ mixing ratio for the soundings during the 2016 Nainital summer campaign $\left(\left\langle\chi_{\mathrm{CFH}}\right\rangle\right)$ (excluding the contaminated profiles); dashed red line: saturation $\mathrm{H}_{2} \mathrm{O}$ mixing ratio $\left(\chi_{\text {sat }}\right)$; other symbols: FLUENT simulation results for the tube average mixing ratios $\left\langle\chi_{\mathrm{H}_{2} \mathrm{O}}\right\rangle_{\text {Vol }}$ in tubes with different ice coating depths $d$ coating the full circumference: $\langle d=15 \mathrm{~cm} ; d=5 \mathrm{~cm} ; \boldsymbol{\nabla} d=1 \mathrm{~cm} ; \star d=0.3 \mathrm{~cm}, \mathrm{x} d=0.15 \mathrm{~cm} ;(1 / 8$ intake tube circumference): $\quad d=1 \mathrm{~cm}, \diamond d=0.45 \mathrm{~cm}$. 

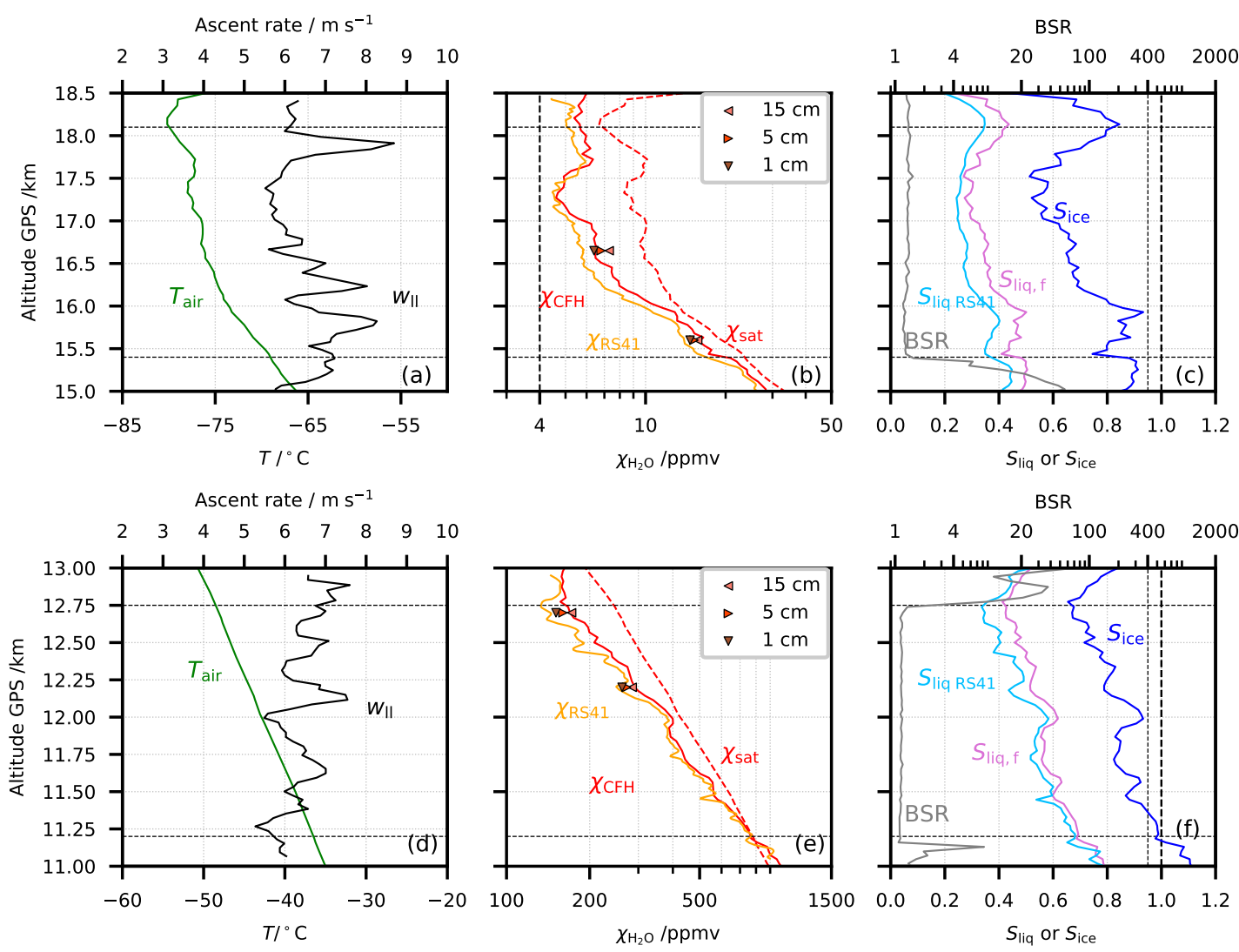

Figure S8: Flight NT029 and FLUENT simulation results for sublimation in the upper troposphere.: (ac) between cirrus cloud and CPT; (d-f) between mixed-phase cloud and cirrus cloud. (a and d) Green: air temperature; black: ascent velocity. ( $b$ and e) Red: $\mathrm{H}_{2} \mathrm{O}$ mixing ratio by the $\mathrm{CFH}$; orange: $\mathrm{H}_{2} \mathrm{O}$ mixing ratio $\mathrm{RS} 41$; dashed red: saturation $\mathrm{H}_{2} \mathrm{O}$ mixing ratio for the air temperature; symbols: FLUENT simulation results for the tube average mixing ratios $\left\langle\chi_{\mathrm{H}_{2} \mathrm{O}}\right\rangle_{\mathrm{Vol}}$ in tubes with different ice coating depths $d$ (full circumference): $\backslash d=15 \mathrm{~cm} ; \quad d=5 \mathrm{~cm} ; \boldsymbol{\nabla} d=1 \mathrm{~cm}$;(c and f) Light blue: saturation over water ( $S_{\text {liq RS41 }}$ ) by the RS41; pink: saturation over water $\left(S_{\text {liq f }}\right)$ from the CFH considering the deposit on the mirror to be frost; blue: ice saturation $\left(S_{\text {ice }}\right)$ from the CFH; grey: $940-n m$ backscatter ratio from the COBALD. Horizontal dashed lines limit the integration interval used for estimating the sublimated ice in the upper troposphere. 
Table S1: FLUENT stratospheric and upper tropospheric simulations input data and results for flight NT029.

\begin{tabular}{|c|c|c|c|c|c|c|c|c|}
\hline \multirow{2}{*}{\multicolumn{6}{|c|}{ Measurements }} & \multicolumn{3}{|c|}{ Simulations } \\
\hline & & & & & & \multirow{2}{*}{$\begin{array}{c}\frac{1 \mathrm{~cm}}{\left\langle\chi_{\mathrm{H}_{2} \mathrm{O}}\right\rangle_{\mathrm{Vol}}} \\
(\mathrm{ppmv})\end{array}$} & \multirow{2}{*}{$\begin{array}{c}5 \mathrm{~cm} \\
\left\langle\chi_{\mathrm{H}_{2} \mathrm{O}}\right\rangle_{\mathrm{Vol}} \\
(\mathrm{ppmv})\end{array}$} & \multirow{2}{*}{$\begin{array}{c}\frac{15 \mathrm{~cm}}{\left\langle\chi_{\mathrm{H}_{2} \mathrm{O}}\right\rangle_{\mathrm{Vol}}} \\
(\mathrm{ppmv})\end{array}$} \\
\hline $\begin{array}{c}h \\
(\mathrm{~km})\end{array}$ & $\begin{array}{c}p \\
(\mathrm{hPa})\end{array}$ & $\begin{array}{c}\mathrm{T} \\
\left({ }^{\circ} \mathrm{C}\right)\end{array}$ & $\begin{array}{c}w_{\|} \\
\left(\mathrm{m} \mathrm{s}^{-1}\right)\end{array}$ & $\begin{array}{c}\chi_{\mathrm{H}_{2} \mathrm{O}} \\
(\mathrm{ppmv})\end{array}$ & $\begin{array}{c}\chi_{\mathrm{H}_{2} \mathrm{O}} \\
\text { reference } \\
\text { (ppmv) }\end{array}$ & & & \\
\hline \multicolumn{9}{|c|}{ Stratospheric: } \\
\hline 30.8 & 11 & -47.7 & 8.1 & 21 & $17^{1}$ & 666 & 2792 & NC \\
\hline 29.7 & 13 & -48.5 & 6.6 & 40 & $12^{1}$ & 521 & 1422 & NC \\
\hline 28.5 & 15 & -51.4 & 7.2 & 71 & $8^{1}$ & 278 & 771 & 1256 \\
\hline 27.4 & 18 & -51.9 & 6.8 & 224 & $7^{1}$ & 205 & 571 & 938 \\
\hline 26.3 & 21 & -52.8 & 6.6 & 291 & $6^{1}$ & 148 & 364 & 684 \\
\hline 25.2 & 25 & -53.6 & 6.9 & 250 & $5^{1}$ & 101 & 285 & 477 \\
\hline 24.1 & 30 & -58.0 & 6.5 & 121 & $5^{1}$ & 47 & 127 & 212 \\
\hline 22.9 & 36 & -58.2 & 6.6 & 88 & $5^{1}$ & 36 & 95 & 160 \\
\hline 21.8 & 43 & -59.4 & 6.2 & 61 & $5^{1}$ & 26 & 66 & 109 \\
\hline 20.7 & 52 & -62.3 & 5.9 & 35 & $4^{1}$ & 15 & 35 & 58 \\
\hline 19.6 & 62 & -68.7 & 6.2 & 13 & $4^{1}$ & 7 & 13 & 20 \\
\hline 18.5 & 75 & -76.7 & 6.1 & 7 & $5^{1}$ & 6 & 6 & 7 \\
\hline 17.3 & 92 & -77.2 & 6.0 & 6 & $6^{1}$ & 7 & 7 & 7 \\
\hline \multicolumn{9}{|c|}{ Tropospheric: } \\
\hline 16.7 & 103 & -76.2 & 5.7 & 6 & $6^{2}$ & 6 & 7 & 7 \\
\hline 15.6 & 123 & -70.7 & 7.0 & 16 & $14^{2}$ & 15 & 15 & 16 \\
\hline 12.7 & 196 & -48.1 & 6.9 & 170 & $142^{2}$ & 151 & 160 & 172 \\
\hline 12.2 & 211 & -44.3 & 7.3 & 289 & $249^{2}$ & 262 & 272 & 285 \\
\hline
\end{tabular}

1: $\left\langle\chi_{\mathrm{CFH}}\right\rangle$

2: $\chi_{\mathrm{RS} 41}$

NC: no convergence 


\section{Flight NT007}

Here we analyse the contamination during flight NT007. The figures shown in this appendix are analogous to several figures shown in the main body of the paper. Figure S9 shows the full profile of flight NT007 on 11 August 2016. As was observed in flights NT011 and NT029, there were contaminated water vapour mixing ratios in the stratosphere, and contrary to the other flights, there was no recovery of the operation of the CFH before balloon burst. The COBALD (panel c) observed two clouds: one extending from $T_{\text {air }}=0{ }^{\circ} \mathrm{C}$ to $T_{\text {air }}=-38{ }^{\circ} \mathrm{C}$, the entire mixed-phase cloud regime; and a second one in the cirrus or ice cloud regime, extending all the way to the tropopause. The lengthy cloud in the mixed-phase cloud regime was likely the cause of the contamination in the stratosphere, specifically two regions of the cloud, which were likely able to support liquid droplets at air temperatures below $0{ }^{\circ} \mathrm{C}$. Details of these two regions of the cloud are shown in Figure S10. Panels (a) and (b) refer to the warmer mixed-phase cloud in air temperatures between -4 and $-7^{\circ} \mathrm{C}$, and between 6.25 and $7 \mathrm{~km}$ altitude. Panels (c) and (d) refer to the colder mixed-phase cloud in air temperatures between -21 and $-25{ }^{\circ} \mathrm{C}$, and between 9.2 and $9.85 \mathrm{~km}$ altitude.

We did not consider the part of the cloud between $5.5 \mathrm{~km}$ and $6.25 \mathrm{~km}$ altitude (see Figure S10b) for the cloud modelling, because we could not be sure if this cloud was liquid, mixed-phase or fully glaciated. $S_{\text {ice }}$ and $S_{\text {liq }}$ measurements are very close to $1 . S_{\text {liq }}$ from the RS41 is not precisely 1 , which is the expected performance of the RS41 in a liquid cloud and fully glaciated clouds are uncommon at these temperatures (Korolev et al., 2003a), however, $\mathrm{Cl}$ from the COBALD is 20 . From $6.25 \mathrm{~km}$ altitude, the CFH was not operating properly (see Figure $\mathrm{S10b}$ ). The deposit on the CFH mirror might have been liquid or a mixture of liquid water and ice, rendering the $S_{\text {ice }}$ measurement by the CFH senseless. The $S_{\text {liq,d }}$ CFH measurement agreed with $S_{\text {liq }}$ by the RS41 to some degree. From $7.5 \mathrm{~km}$ altitude, the CFH showed controller oscillations (Vömel et al., 2016) until the freezing cycle re-established normal operation by creating a stable ice layer in the mirror. To continue this analysis we calculated $S_{\text {ice }}$ from the RS41 (black) in Figure S10b. At $6.25 \mathrm{~km}$ altitude, there was supersaturation over ice and sub-saturation over water, these conditions likely allowed big supercooled liquid droplets to exist and impact the top of the intake tube. Above $7 \mathrm{~km}$ altitude, the cloud was sub-saturated in relation to ice, which is consistent with a sublimating ice cloud. The presence of a cloud was supported by the COBALD BSR. At no other point within the cloud was $S_{\text {liq }}$ equal to 1 . However, between 9.2 and $9.85 \mathrm{~km}$ altitude, Figure S10c-d, there was a similar scenario to the one explored for the mixed-phase clouds of flights NT011 and NT029, with $S_{\text {ice }}=1.2$ and $S_{\text {liq }}=0.95$.

We modelled the two regions of the cloud likely to support big liquid droplets at air temperatures below $0{ }^{\circ} \mathrm{C}$. The results are presented in Figure S11. Panels (a) and (b) refer to the warm mixed-phase cloud and panels (c) and (d) refer to the cold mixed-phase cloud. The lower and upper estimates of LWC (see Table 1 of Jorge et al, 2020) were defined by the ice sublimated in the stratosphere and upper troposphere (see Table 3 of Jorge et al, 2020). However, for flight NT007, both the upper and lower estimates of LWC are lower estimates, because the water vapour measurement in the stratosphere by the CFH did not recover. We have considered similar droplets and ice crystal sizes for the distributions of both NT007 clouds. With the exception, that we considered bigger size droplets of $r_{\text {liq, } 3}=200 \mu \mathrm{m}$ to be present in cloud 1, between 6.25 and $7 \mathrm{~km}$ altitude, and not in cloud 2, between 9.2 and $9.85 \mathrm{~km}$ altitude. With the prescribed initial liquid droplet and ice crystal distributions, liquid droplets existed in cloud 1 at the observed $S_{\text {ice }}$ and $S_{\text {liq }}$ for about 1 hour, and in cloud 2 for about 12 minutes. In both cases, reasonable time for the payload to travel through them at about 3 to $5 \mathrm{~m} \mathrm{~s}^{-1}$ ascent velocity.

Figure S12 shows the pendulum analysis for the two mixed-phase cloud regions of NT007. Panel (a) refers to the entire flight, panels (b) and (c) refer to the warmer cloud region (cloud 1), and panels (d) and (e) refer to the colder cloud region (cloud 2). The amplitude of the oscillation in these two cloud regions was smaller than the ones observed for the clouds of flights NT011 and NT029. The maximum amplitude of oscillation for the two 
clouds was about 25 to $30 \mathrm{~m}$, while for the clouds of NT011 and NT029 it was $40 \mathrm{~m}$. The smaller amplitudes were related to the slower ascent velocities of this flight. The ascent velocities $\left(w_{\|}\right)$were smaller, but so were the perpendicular velocities $\left(v_{\perp}\right)$ experienced at the intake tube inlet. Together they still caused big impact angles $(\beta)$, as can be seen in Figure S13. Panels (a), (b) and (c) refer to the warmer cloud region (cloud 1 ), and panels (d), (e) and (f) refer to the colder cloud region (cloud 2).

Figure S14 shows the FLUENT simulation results for the collision/ freezing efficiency of hydrometeors in the intake tube for the mixed-phase cloud 1 of flight NT007. For this simulation we considered the presence of small droplets $\left(r_{\text {liq }}=10 \mu \mathrm{m}\right)$ inside the mixed-phase cloud $\left(S_{\text {liq }} \sim 1\right)$. As mentioned in Section 4.2.2 of Jorge et al, 2020, the small droplets were more connected with the flow and their collision/ freezing efficiency was much smaller than for bigger droplets. At small impact angles, e.g. $13^{\circ}$ shown in Figure S14a, most of the droplets, which froze in the intake tube, froze in the 'rest of the tube' category, most likely below the mirror holder. At impact angles of $50^{\circ}$ less than $50 \%$ of the small liquid droplets collided with the top of the intake tube, unlike the bigger droplets (e.g. $r_{\text {liq }}=100 \mu \mathrm{m}$ droplets), $100 \%$ of which froze on collision with the first $3 \mathrm{~cm}$ of the intake tube. The freezing efficiency of the bigger droplets, $r_{\text {liq }}=200 \mu \mathrm{m}$, did not differ significantly from the freezing efficiency of $100-\mu \mathrm{m}$-radius-droplets. Figure S15 shows the FLUENT simulation results for collision/ freezing efficiency of hydrometeors in the intake tube for the cold cloud region (cloud 2) of flight NT007. The thickest ice layer inside the intake tube after both clouds, the layer between $1-2 \mathrm{~cm}$, was only $25 \mu \mathrm{m}$ thick (see Figure S14f and $\mathrm{S15g}$ ), if we considered the upper estimate of LWC inside the cloud. This would represent a $0.4 \%$ decrease of air flow through the intake tube.

Figure S16 shows the stratosphere of flight NT007, and the FLUENT simulation results (see also Table S2). The ascent velocity of NT007 showed a well defined oscillation with a spacial frequency of $1 \mathrm{~km}^{-1}$ altitude and amplitude of about $1 \mathrm{~m} \mathrm{~s}^{-1}$ ( black line panel (a)). On average in the stratosphere the ascent of flight NT007 was slower than that of flights NT011 and NT029 (3.5 m s${ }^{-1}$ vs $\left.5.5 \mathrm{~m} \mathrm{~s}^{1}\right)$. The temperature in the stratosphere for flight NTO07 showed a wave-like behaviour around the average temperature profile of the season. From the comparison of the simulation results for $\chi_{\mathrm{H}_{2} \mathrm{O}}$ in Figure S16b, we concluded, as for flight NT011 and NT029, that the simulations with $5 \mathrm{~cm}$ ice coverage of the intake tube yielded the best description of the observations up to $24 \mathrm{~km}$ altitude. Above $24 \mathrm{~km}$ altitude, the $5 \mathrm{~cm}$ ice covered intake tube simulation over-estimated the observed $\chi_{\mathrm{H}_{2} \mathrm{O}}$ by the $\mathrm{CFH}$. This was consistent with the intake tube ice covered surface decreasing, however, the decrease and recovery was not as observed in the two other flights. The $1 \mathrm{~cm}$ ice covered intake tube simulation underestimated the observed $\chi_{\mathrm{H}_{2} \mathrm{O}}$ up to balloon burst at $31 \mathrm{~km}$ altitude. The ice coverage of the intake tube in this flight was most likely different than in the other flights. The warm cloud in this flight had possibly a more uniform droplet size distribution, which would translate in a more uniform coverage of the intake tube and the observed, more persistent, contamination of the $\mathrm{H}_{2} \mathrm{O}$ measurements. The integrated excess water vapour in the stratosphere for flight NT007 was $65.5 \mathrm{mg}$.

To evaluate the upper tropospheric contamination during flight NT007, we looked at the interval between the mixed-phase cloud and the cirrus cloud shown in Figure S17. From $12.5 \mathrm{~km}$ altitude, above the CFH freezing cycle, the dry bias between the RS41 and the CFH was visible. We ran simulations for two altitudes, 13.0 and $14.1 \mathrm{~km}$ (see Table S2). The simulation with a $15 \mathrm{~cm}$ long ice coverage inside the intake tubes described the observed $\chi_{\mathrm{H}_{2} \mathrm{O}}$ by the $\mathrm{CFH}$ the best. In this flight there was an unique observation at $13.8 \mathrm{~km}$ altitude when $S_{\text {ice }}$ approached 1 under clear sky conditions (see Figure S17c) and the CFH under-estimated the water vapour measurement in relation to the RS41. Under those conditions, the icy intake tube top had the opposite effect in contaminating the CFH measurement. It depleted the gas phase water vapour, and grew the ice coverage, reducing the supersaturation which in a clean intake tube case would have been observed. The integrated water vapour for the upper troposphere of flight NT007 was $47.5 \mathrm{mg}$ (see Table 3 of Jorge et al.,2020). In total more $113 \mathrm{mg}$ of water was observed in flight NT007 than what was expected without contamination. 

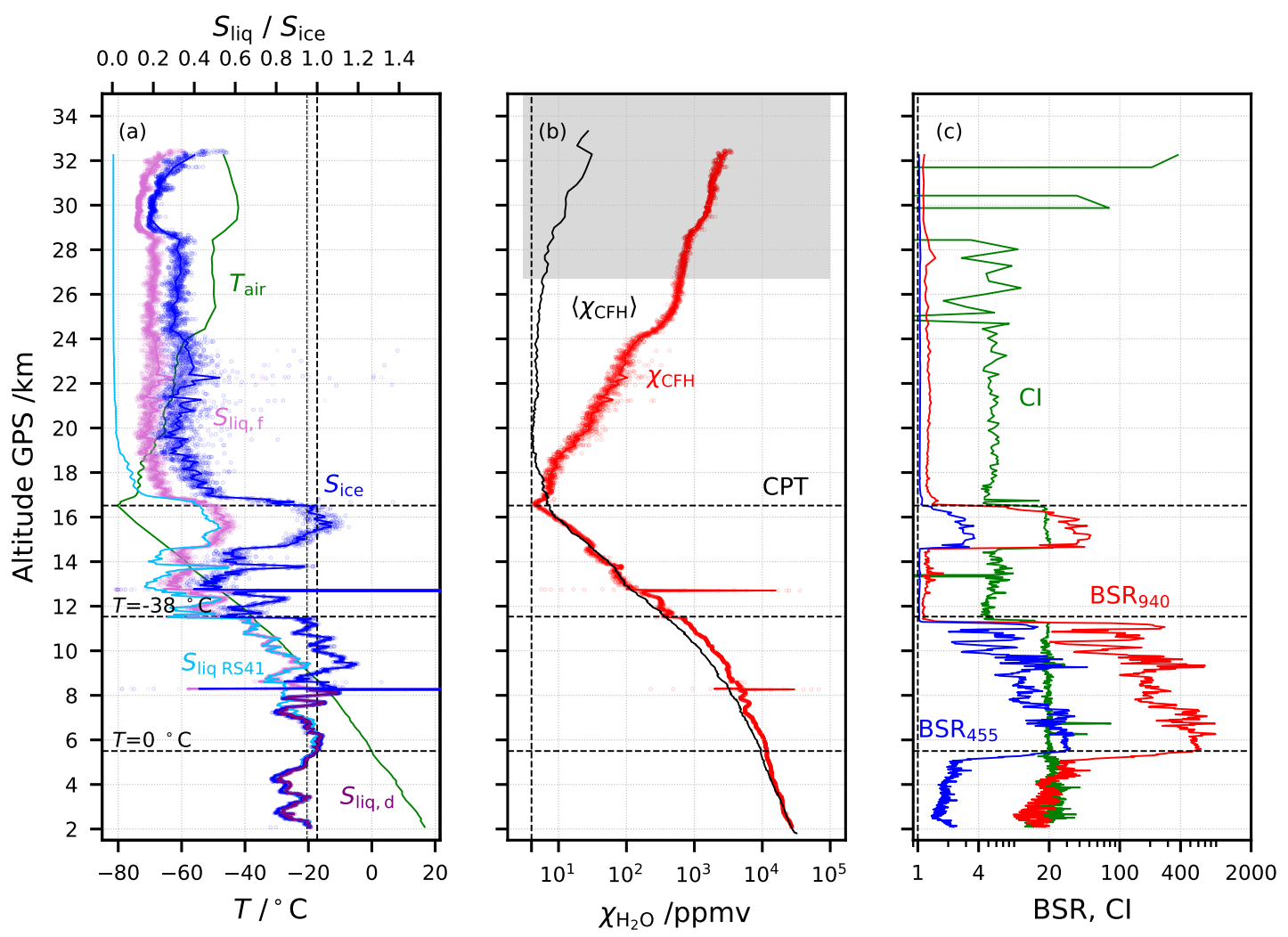

Figure S9: Flight NT007 in Nainital, India, on 11 August 2016. Lines: 1 hPa interval averaged values. Dots: $1 \mathrm{~s}$ data. (a) Green: air temperature measurement from the Vaisala RS41; light blue: saturation over water ( $\left.S_{\text {liq RS41 }}\right)$ measured by the RS41; blue: ice saturation $\left(S_{\text {ice }}\right)$ from the CFH; purple: saturation over water ( $S_{\text {liq, }}$ ) from the CFH considering the deposit on the mirror to be dew; pink: saturation over water $\left(S_{\text {liq, }}\right)$ from the CFH considering the deposit on the mirror to be frost. Note that the condensate on the CFH mirror was forced to turn from dew to frost after the freezing cycle, at $T_{\text {frost }}=-15^{\circ} \mathrm{C}$. (b) Red: $\mathrm{H}_{2} \mathrm{O}$ mixing ratio from the $\mathrm{CFH}$ in ppmv; black: season average $\mathrm{H}_{2} \mathrm{O}$ mixing ratio excluding contaminated CFH profiles for the Nainital 2016 summer campaign (Brunamonti et al., 2018). Highlighted values with grey shading above the $20-\mathrm{hPa}$ level are possibly contaminated by out gassing from the balloon envelope. 'CPT' marks the cold point tropopause. (c) Red: 940-nm backscatter ratio from the COBALD; blue: same for $455 \mathrm{~nm}$; green: color index (CI) from the COBALD. 

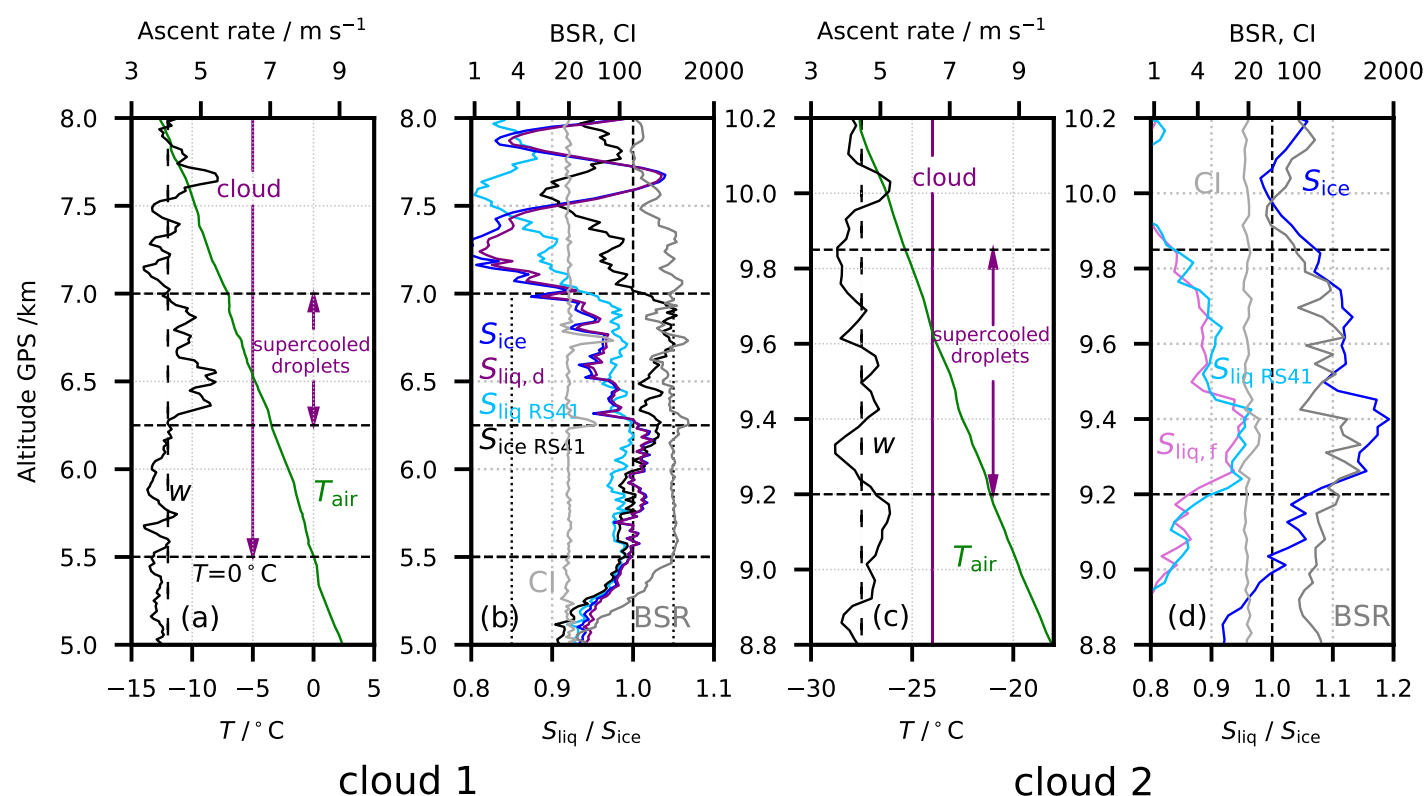

cloud 1

cloud 2

Figure S10: Mixed-phase cloud details of flight NT007. Lines: $1 \mathrm{hPa}$ interval averaged values. (a-b) Cloud 1; (c-d) cloud 2. (a and c) Green: air temperature; black: ascent velocity by the RS41 in $\mathrm{m} \mathrm{s}^{-1}$. (b and d) Light blue: saturation over water ( $\left.S_{\text {liq RS41 }}\right)$ by the RS41; purple: saturation over water $\left(S_{\text {liq,d }}\right)$ from the CFH considering the deposit on the mirror to be dew; pink: saturation over water $\left(S_{\text {liq, } f}\right)$ from the CFH considering the deposit on the mirror to be frost; blue: ice saturation $\left(S_{\text {ice }}\right)$ from the CFH; black: ice saturation ( $S_{\text {ice RS41 }}$ ) from the RS41; dark grey: $940-n m$ backscatter ratio from the COBALD; light grey: color index $(\mathrm{Cl})$ from the COBALD. Horizontal dashed lines mark supercooled droplet region and $T_{\text {air }}=0^{\circ} \mathrm{C}$. 


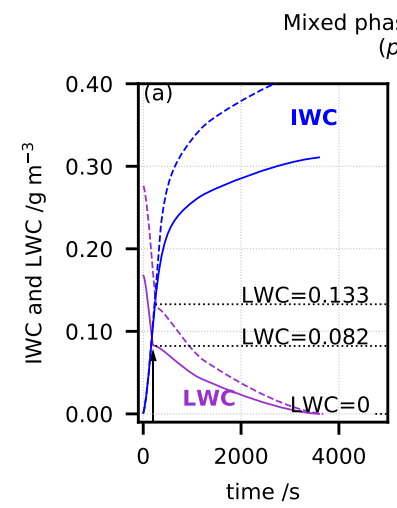

se cloud simulation for NT007 $\left(p=310 \mathrm{hPa}, T=-20^{\circ} \mathrm{C}\right)$

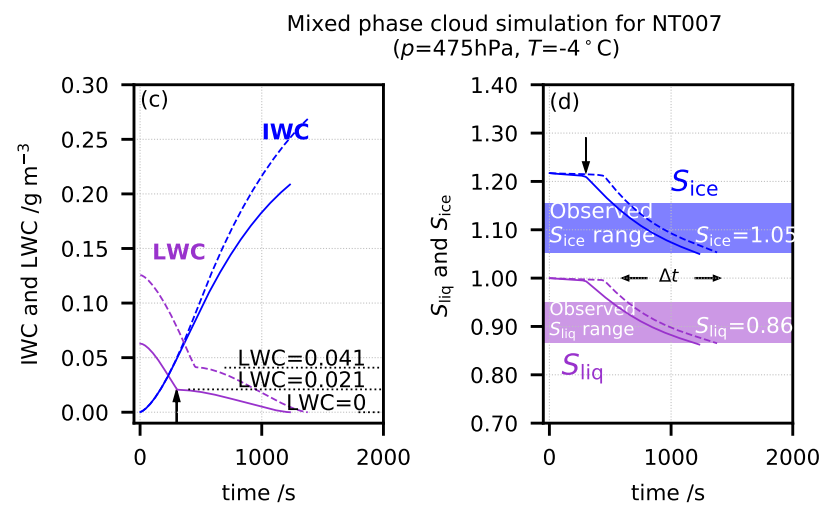

Figure S11: Modelling of the Wegener-Bergeron-Findeisen process in mixed-phase cloud demonstrating that flight NT007 likely encountered supercooled liquid droplets in two occasions: (a-b) refer to cloud 1 between 6.25 and $7 \mathrm{~km}$ altitude and (c-d) refer to cloud 2 between 9.2 and $9.85 \mathrm{~km}$ altitude. Solid lines: lower estimate of liquid water content (LWC). Dashed lines: upper estimate (see text). (ab) Initial size distributions for lower estimate simulation: $n_{\text {ice }}=0.02 \mathrm{~cm}^{-3}, r_{\text {ice }}=10 \mu \mathrm{m} ; n_{\text {liq }, 1}=20 \mathrm{~cm}^{-3}$, $r_{\text {liq }, 1}=10 \mu \mathrm{m} ; n_{\text {liq }, 2}=0.004 \mathrm{~cm}^{-3}, r_{\text {liq }, 2}=100 \mu \mathrm{m} ; n_{\text {liq }, 3}=0.002 \mathrm{~cm}^{-3}, r_{\text {liq }, 3}=200 \mu \mathrm{m}$. Initial size distributions for upper estimate simulation are identical but with $75 \%$ larger $n_{\text {liq, } 1}$ and $n_{\text {liq,2-3. (a) Blue: }}$ ice water content (IWC); purple: liquid water content (LWC); vertical arrows: time when smaller liquid droplets fully evaporated. (b) Blue: ice saturation ratio $\left(S_{\text {ice }}\right)$; purple: liquid water saturation ratio $\left(S_{\text {liq }}\right)$ for lower and upper estimates. Glaciation times of small droplets $\tau_{g, 1} \sim 4$ minutes, of big droplets $\tau_{g, 2-3} \sim 60$ minutes. Shaded saturated ratios: observed ranges from Figure S10b. The computed time interval with $S_{\text {ice }}$ and $S_{\text {liq }}$ matching flight observations is $\Delta t \sim 60$ minutes. (c-d) Initial size distributions for lower estimate simulation: $n_{\text {ice }}=0.02 \mathrm{~cm}^{-3}, r_{\text {ice }}=10 \mu \mathrm{m} ; n_{\text {liq }, 1}=10 \mathrm{~cm}^{-3}, r_{\text {liq }, 1}=10 \mu \mathrm{m}$; $n_{\text {liq }, 2}=0.005 \mathrm{~cm}^{-3}, r_{\text {liq }, 2}=100 \mu \mathrm{m}$. Initial size distributions for upper estimate simulation are identical but with $2 \times$ larger $n_{\text {liq, } 2 .}$ (c) Blue: ice water content (IWC); purple: liquid water content (LWC); vertical arrows: time when smaller liquid droplets fully evaporated. (d) Blue: ice saturation ratio $\left(S_{\text {ice }}\right)$; purple: liquid water saturation ratio $\left(S_{\text {liq }}\right)$ for lower and upper estimates. Glaciation times of small droplets $\tau_{g, 1} \sim 8$ minutes, of big droplets $\tau_{g, 2} \sim 18$ minutes. Shaded saturation ratios: observed ranges from Figure S10d. The computed time interval with $S_{\text {ice }}$ and $S_{\text {liq }}$ matching flight observations is $\Delta t \sim 12$ minutes. 

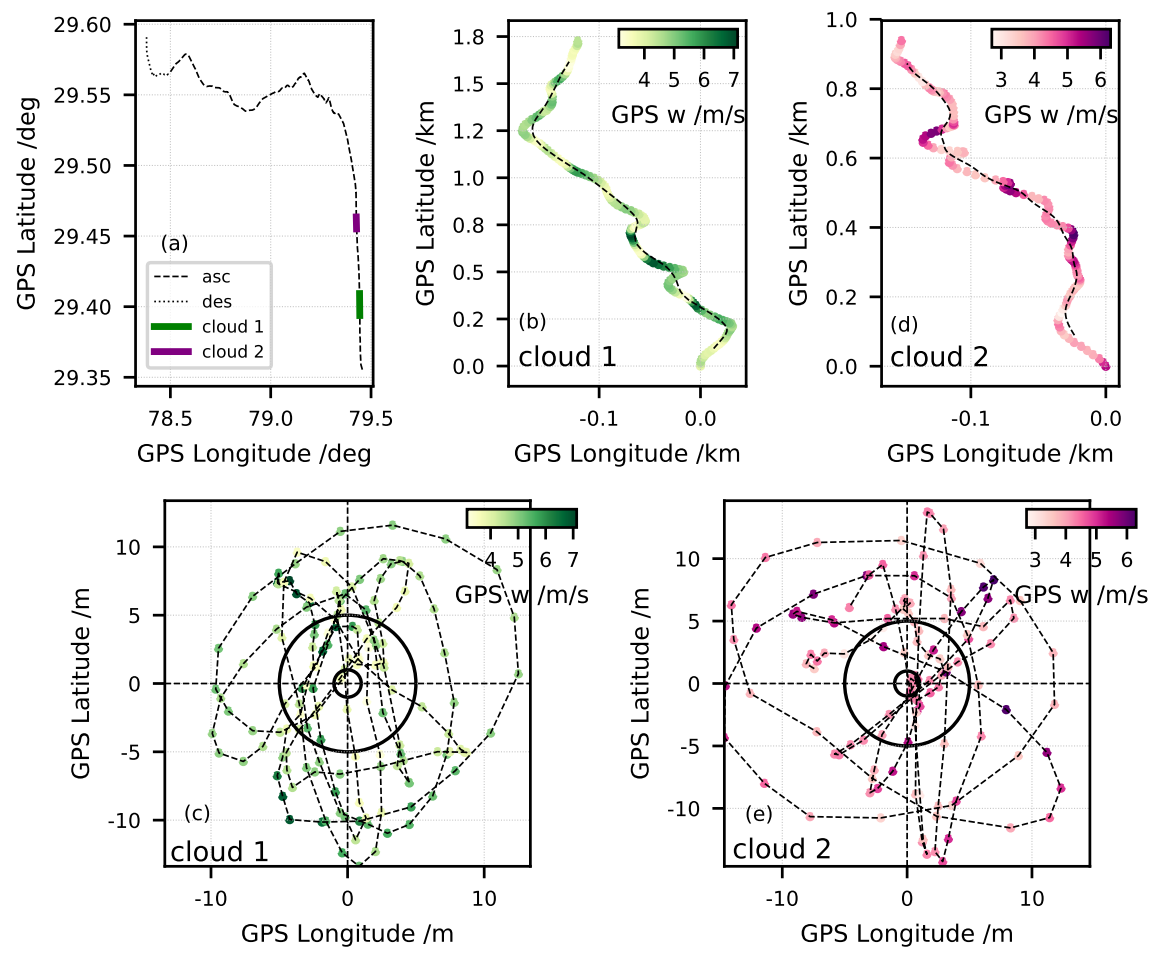

Figure S12: Pendulum analysis for mixed-phase clouds of flight NT007. (a) Payload trajectory: ascent (dashed), descent (dotted), mixed-phase cloud 1 between 6.25 and $7 \mathrm{~km}$ altitude (thick green line) and mixed-phase cloud 2 between 9.2 and $9.85 \mathrm{~km}$ altitude (thick purple line). (b) Zoom in on the mixed-phase cloud 1 with 1-second GPS data of payload trajectory (symbols) and balloon trajectory (dashed). (c) Detrended payload oscillations; approximate balloon sizes on the ground $(r=1 \mathrm{~m})$ and at burst $(r=5 \mathrm{~m})$ are shown by two circles. (d) Same as in (b) but for cloud 2. (e) Same as in (c) but for cloud 2. Colour code in (b-e): balloon ascent velocity. 

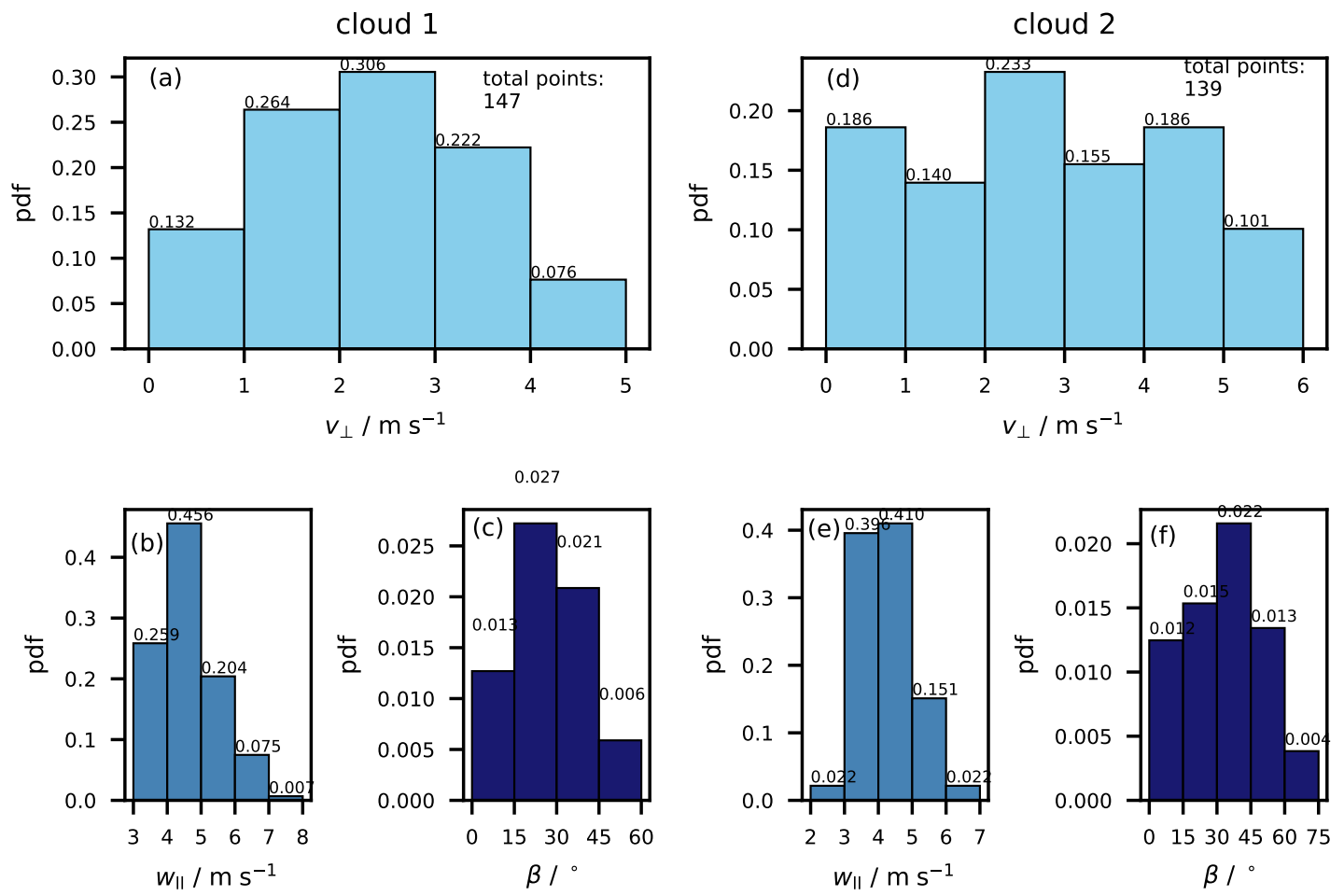

Figure S13: Probability density functions (pdf) of impact parameters at the inlet plane of the CFH intake tube during the passage through the mixed-phase cloud of flight NT007. (a-c) cloud 1 between 6.25 and $7 \mathrm{~km}$ altitude; (d-f) refer to cloud 2 between 9.2 and $9.85 \mathrm{~km}$ altitude. ( $a$ and d) Velocity $v_{\perp}$ perpendicular to the tube walls; ( $b$ and e) velocity $w_{\|}$parallel to the axis of the tube; (c and f) impact angle $(\beta)$. 


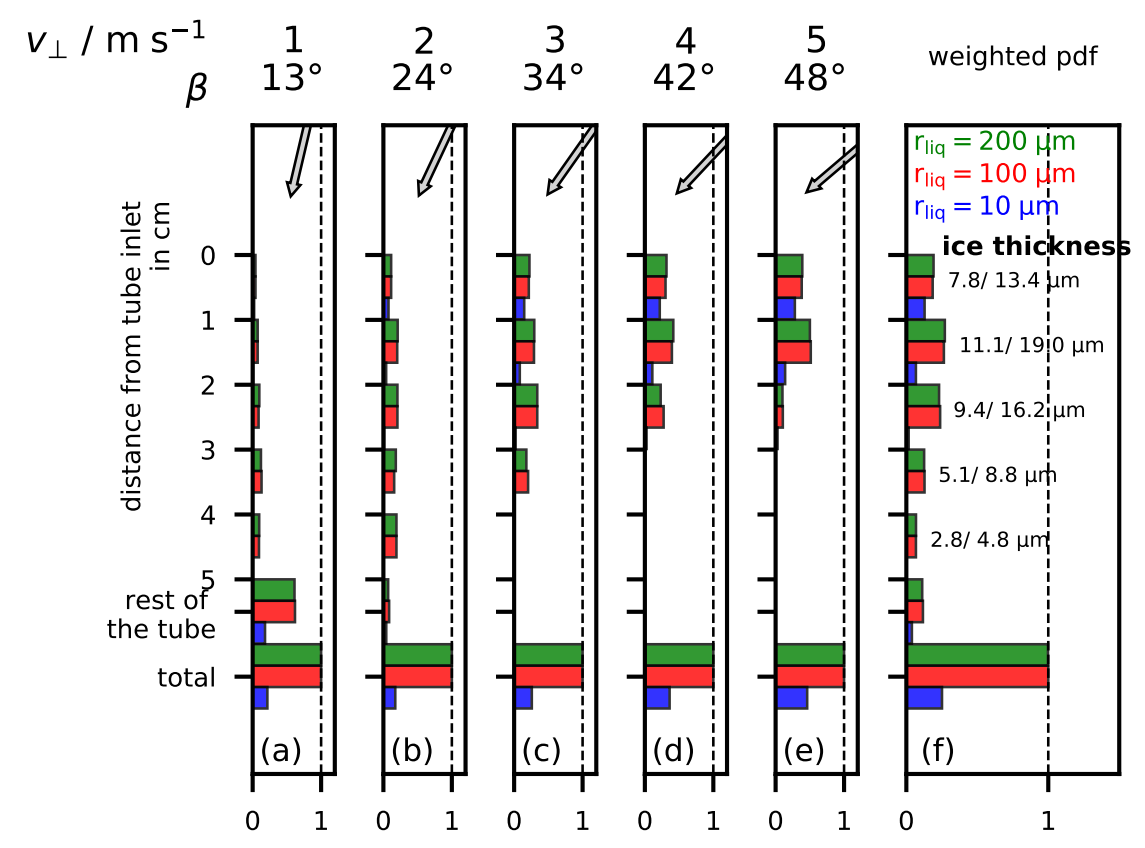

Figure S14: Collision/freezing efficiency of hydrometeors in the intake tube for mixed-phase cloud 1 of flight NT007 with average vertical inlet velocity $w_{\|}=4.5 \mathrm{~m} \mathrm{~s}^{-1} \cdot r_{\text {liq }}=200 \mu \mathrm{m}$ (green), $r_{\text {liq }}=100 \mu \mathrm{m}$ (red), $r_{\text {liq }}=10 \mu \mathrm{m}$ (blue). (a-e) Freezing efficiency for various velocities $\left(v_{\perp}\right)$ perpendicular to the tube walls: (a) $1 \mathrm{~m} \mathrm{~s}^{-1}, 13^{\circ}$; (b) $2 \mathrm{~m} \mathrm{~s}^{-1}, 24^{\circ}$; (c) $3 \mathrm{~m} \mathrm{~s}^{-1}, 34^{\circ}$; (d) $4 \mathrm{~m} \mathrm{~s}^{-1}, 42^{\circ}$; (e) $5 \mathrm{~m} \mathrm{~s}^{-1}, 48^{\circ}$. The 'rest of the tube' takes account of all collisions occurring deeper than $5 \mathrm{~cm}$ inside the tube, including the mirror holder. (f) Weighted sum of the efficiencies in panels (a-e) by the horizontal velocity pdf of Figure S13a, in front of each bar we write the thickness of the subsequent ice layer considering radial homogeneous cover of the intake tube and the lower (left) and upper (right) LWC estimate for the cloud. 


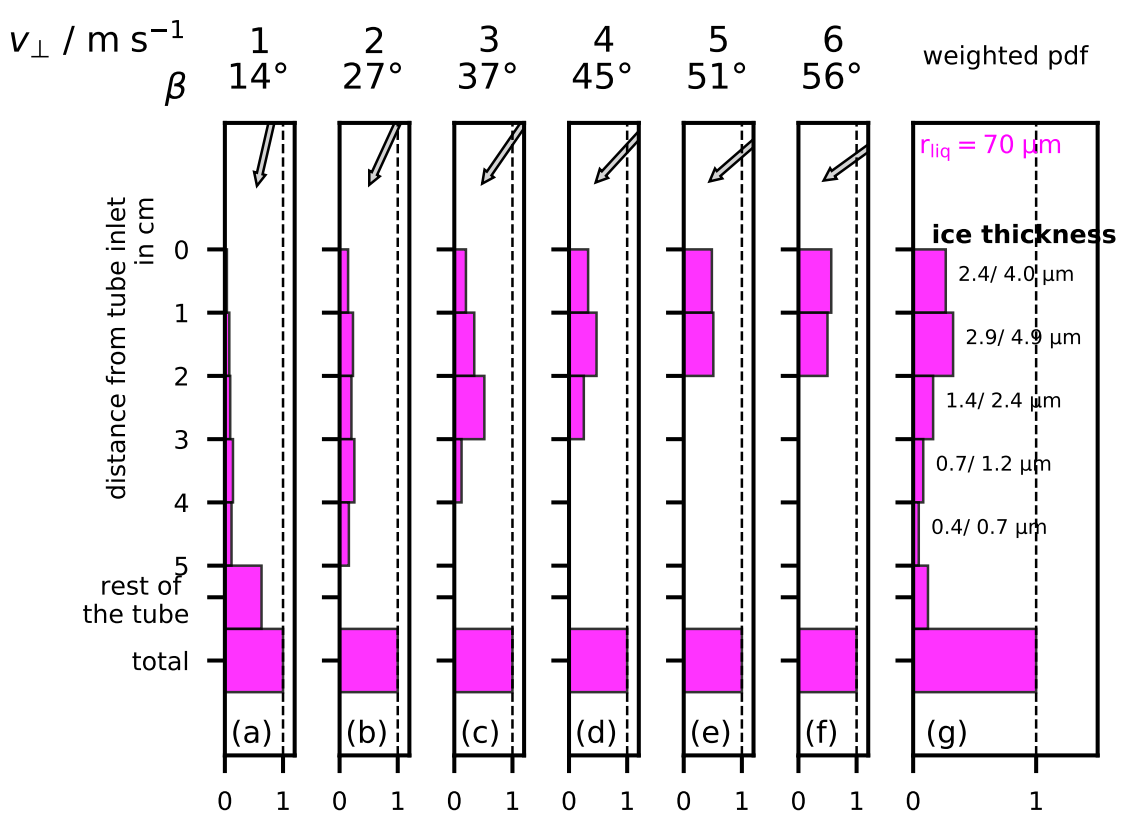

Figure S15: Collision/freezing efficiency of hydrometeors in the intake tube for mixed-phase cloud 2 of flight NT007 with average vertical inlet velocity $w_{\|}=4.0 \mathrm{~m} \mathrm{~s}^{-1} \cdot r_{\text {liq }}=70 \mu \mathrm{m}$ (pink). (a-f) Freezing efficiency for various velocities $\left(v_{\perp}\right)$ perpendicular to the tube walls: (a) $1 \mathrm{~m} \mathrm{~s}^{-1}, 14^{\circ}$; (b) $2 \mathrm{~m} \mathrm{~s}^{-1}$, $27^{\circ}$; (c) $3 \mathrm{~m} \mathrm{~s}^{-1}, 37^{\circ}$; (d) $4 \mathrm{~m} \mathrm{~s}^{-1}, 45^{\circ}$; (e) $5 \mathrm{~m} \mathrm{~s}^{-1}, 51^{\circ}$; (e) $6 \mathrm{~m} \mathrm{~s}^{-1}, 56^{\circ}$. The 'rest of the tube' takes account of all collisions occurring deeper than $5 \mathrm{~cm}$ inside the tube, including the mirror holder. (g) Weighted sum of the efficiencies in panels (a-f) by the horizontal velocity pdf of Figure S13d, in front of each bar we write the thickness of the subsequent ice layer considering radial homogeneous cover of the intake tube and the lower (left) and upper (right) LWC estimate for the cloud. 

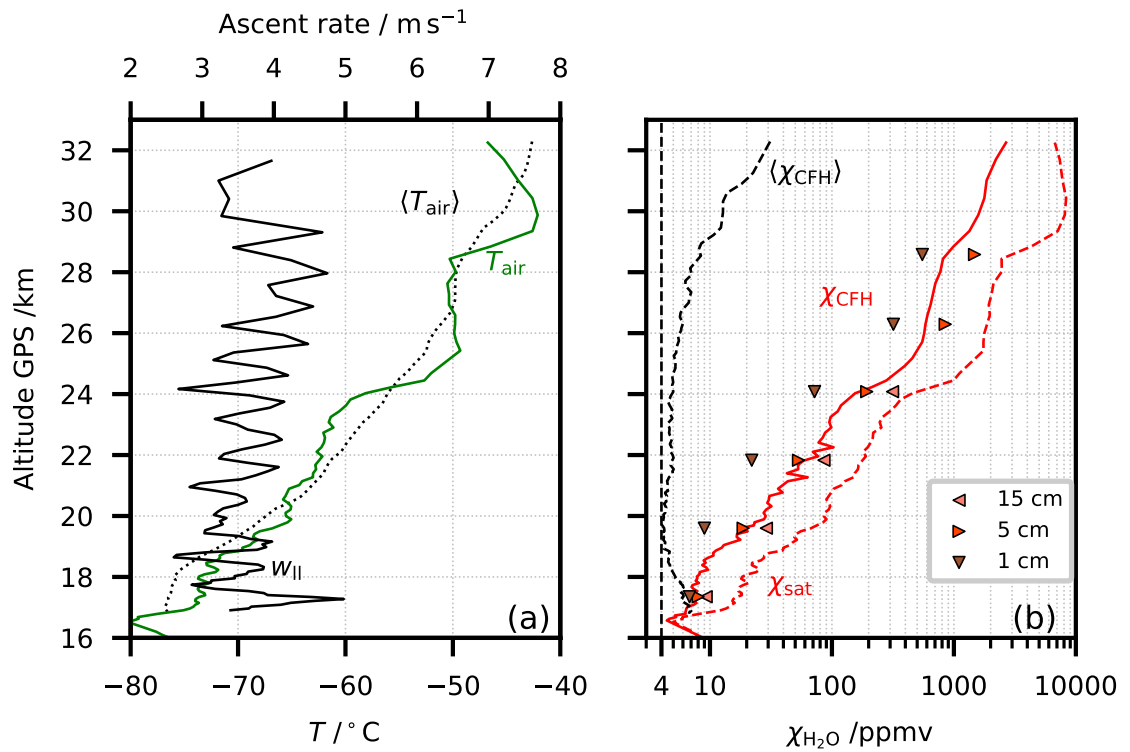

Figure S16: Flight NT007 and FLUENT simulation results for sublimation of ice in the intake tube in the stratosphere. (a) Green line: measured air temperature $T_{\text {air }}$; dotted black line: average air temperature for the 2016 Nainital summer campaign; solid black line: ascent velocity; (b) Solid red line: $\mathrm{H}_{2} \mathrm{O}$ mixing ratio measured by the CFH during NT007 ( $\left.\chi_{\mathrm{CFH}}\right)$; dashed black line: average $\mathrm{H}_{2} \mathrm{O}$ mixing ratio of the soundings during the 2016 Nainital summer campaign $\left(\left\langle\chi_{\mathrm{CFH}}\right\rangle\right)$ (excluding the contaminated profiles); dashed red line: saturation $\mathrm{H}_{2} \mathrm{O}$ mixing ratio $\left(\chi_{\text {sat }}\right)$; other symbols: FLUENT simulation results for the tube average mixing ratios $\left\langle\chi_{\mathrm{H}_{2} \mathrm{O}}\right\rangle_{\text {Vol }}$ in tubes with different ice coating depths $d$ coating the full circumference: $\varangle d=15 \mathrm{~cm} ; d=5 \mathrm{~cm} ; \boldsymbol{\nabla} d=1 \mathrm{~cm}$ 

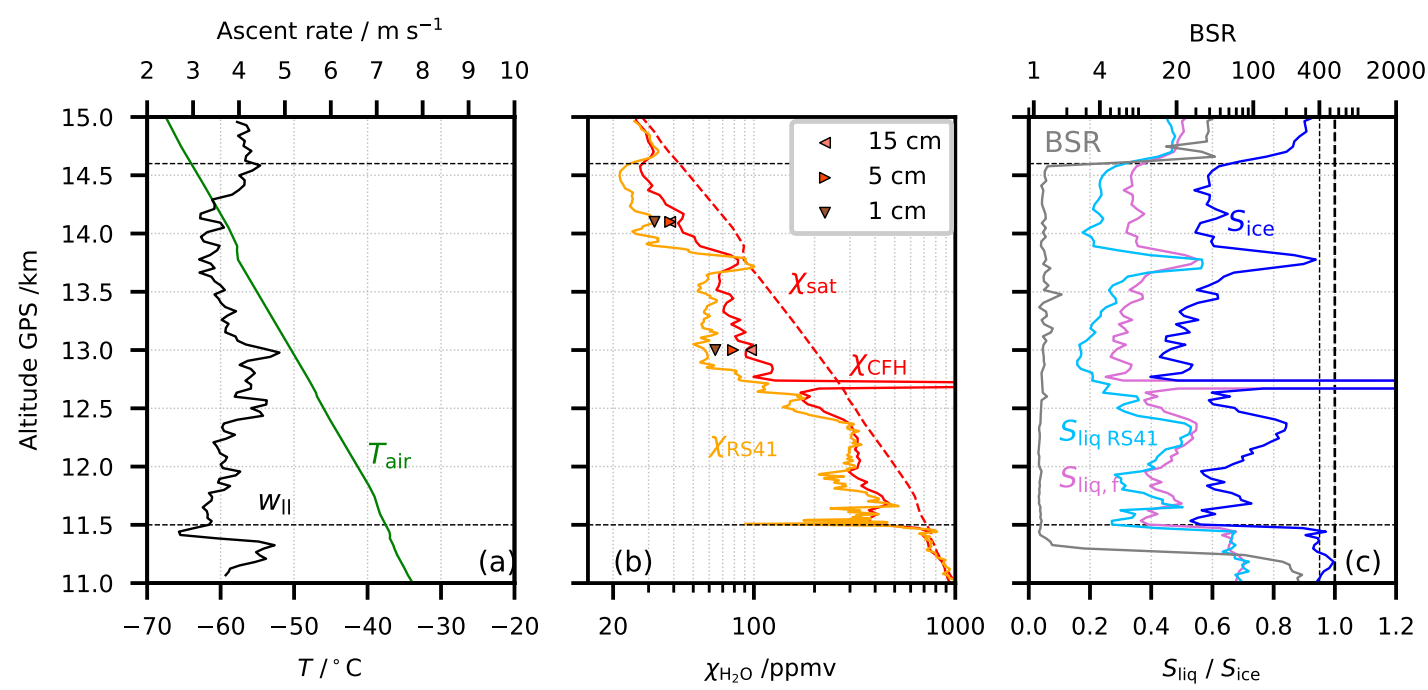

Figure S17: Flight NT007 and FLUENT simulation results for sublimation in the upper troposphere. (a) Green: air temperature; black: ascent velocity. (b) Red: $\mathrm{H}_{2} \mathrm{O}$ mixing ratio by the $\mathrm{CFH}$; orange: $\mathrm{H}_{2} \mathrm{O}$ mixing ratio $\mathrm{RS} 41$; dashed red: saturation $\mathrm{H}_{2} \mathrm{O}$ mixing ratio for the air temperature; symbols: FLUENT simulation results for the tube average mixing ratios $\left\langle\chi_{\mathrm{H}_{2} \mathrm{O}}\right\rangle_{\text {Vol }}$ in tubes with different ice coating depths $d$ (full circumference): $\varangle d=15 \mathrm{~cm} ; \quad d=5 \mathrm{~cm} ; \boldsymbol{\nabla} d=1 \mathrm{~cm}$; (c) Light blue: saturation over water ( $\left.S_{\text {liq RS41 }}\right)$ by the RS41; pink: saturation over water $\left(S_{\text {liq f }}\right)$ from the CFH considering the deposit on the mirror to be frost; blue: ice saturation $\left(S_{\text {ice }}\right)$ from the CFH; grey: 940-nm backscatter ratio from the COBALD. Horizontal dashed lines limit the integration interval used for estimating the sublimated ice in the upper troposphere. 
Table S2: FLUENT stratospheric and upper tropospheric simulations input data and results for flight NT007.

\begin{tabular}{|c|c|c|c|c|c|c|c|c|}
\hline \multirow{2}{*}{\multicolumn{6}{|c|}{ Measurements }} & \multicolumn{3}{|c|}{ Simulations } \\
\hline & & & & & & \multirow{2}{*}{$\begin{array}{c}1 \mathrm{~cm} \\
\left\langle\chi_{\mathrm{H}_{2} \mathrm{O}}\right\rangle_{\mathrm{Vol}} \\
(\mathrm{ppmv})\end{array}$} & \multirow{2}{*}{ 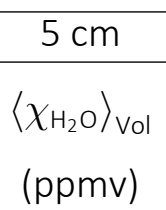 } & \multirow{2}{*}{$\begin{array}{c}15 \mathrm{~cm} \\
\left\langle\chi_{\mathrm{H}_{2} \mathrm{O}}\right\rangle_{\mathrm{Vol}} \\
(\mathrm{ppmv})\end{array}$} \\
\hline $\begin{array}{c}h \\
(\mathrm{~km})\end{array}$ & $\begin{array}{c}p \\
(\mathrm{hPa})\end{array}$ & $\begin{array}{c}\mathrm{T} \\
\left({ }^{\circ} \mathrm{C}\right)\end{array}$ & $\begin{array}{c}w_{\|} \\
\left(\mathrm{m} \mathrm{s}^{-1}\right)\end{array}$ & $\begin{array}{c}\chi_{\mathrm{H}_{2} \mathrm{O}} \\
\text { (ppmv) }\end{array}$ & $\begin{array}{c}\chi_{\mathrm{H}_{2} \mathrm{O}} \\
\text { reference } \\
\text { (ppmv) }\end{array}$ & & & \\
\hline \multicolumn{9}{|c|}{ Stratospheric: } \\
\hline 30.7 & 11 & -43.4 & 3.3 & 1831 & $16^{1}$ & NC & NC & NC \\
\hline 28.6 & 15 & -48.3 & 4.0 & 897 & $8^{1}$ & 551 & 1477 & NC \\
\hline 26.3 & 22 & -49.9 & 3.9 & 590 & $6^{1}$ & 319 & 849 & NC \\
\hline 24.1 & 30 & -56.8 & 3.5 & 190 & $5^{1}$ & 72 & 193 & 314 \\
\hline 21.8 & 43 & -62.6 & 3.7 & 66 & $5^{1}$ & 22 & 53 & 86 \\
\hline 19.6 & 63 & -67.0 & 3.4 & 21 & $4^{1}$ & 9 & 19 & 29 \\
\hline 17.4 & 92 & -74.0 & 3.8 & 7 & $6^{1}$ & 7 & 8 & 9 \\
\hline \multicolumn{9}{|c|}{ Tropospheric: } \\
\hline 14.1 & 158 & -59.6 & 3.1 & 44 & $31^{2}$ & 32 & 38 & 38 \\
\hline 13.0 & 188 & -50.4 & 4.5 & 93 & $56^{2}$ & 64 & 79 & 97 \\
\hline
\end{tabular}

1: $\left\langle\chi_{\mathrm{CFH}}\right\rangle$

2: $\chi_{\mathrm{RS} 41}$

NC: no convergence 


\section{References}

Brunamonti, S., Jorge, T., Oelsner, P., Hanumanthu, S., Singh, B. B., Kumar, K. R., Sonbawne, S., Meier, S., Singh, D., Wienhold, F. G., Luo, B. P., Böttcher, M., Poltera, Y., Jauhiainen, H., Kayastha, R., Dirksen, R., Naja, M., Rex, M., Fadnavis, S., and Peter, T.: Balloon-borne measurements of temperature, water vapor, ozone and aerosol backscatter at the southern slopes of the Himalayas during StratoClim 2016-2017, Atmospheric Chemistry and Physics, 2018, 1-38, https://doi.org/10.5194/acp-2018-222, 2018.

DeMott, P. J., Prenni, A. J., Liu, X., Kreidenweis, S. M., Petters, M. D., Twohy, C. H., Richardson, M. S., Eidhammer, T., and Rogers, D. C.: Predicting global atmospheric ice nuclei distributions and their impacts on climate, Proc Natl Acad Sci U S A, 107, 11217-22, https://doi.org/10.1073/pnas.0910818107, URL https://www.ncbi.nlm.nih.gov/pubmed/20534566, 2010.

Korolev, A. V., Isaac, G. A., Cober, S. G., Strapp, J. W., and Hallett, J.: Microphysical characterization of mixed-phase clouds, Quarterly Journal of the Royal Meteorological Society, 129, 39-65, https://doi.org/10.1256/qj.01.204, 2003a.

Vömel, H., Naebert, T., Dirksen, R., and Sommer, M.: An update on the uncertainties of water vapor measurements using cryogenic frost point hygrometers, Atmospheric Measurement Techniques, 9, 3755-3768, https://doi.org/10.5194/amt-9-3755-2016, 2016. 